should be Inverury, and the next page has a cruel mutilation of Le Gros Guignon, while the reference to Archaeological Journal on the page before should be to the York volume ( 1848 ).

Following an excellent example, Mr. Mortimer furnishes relic-tables with all necessary details at the end of the volume, together with a copious index. Comparison with Canon Greenwell's table shows a very large proportion of primary interments, there being in one case as many as seventeen, to three secondary; but in a matter of this kind different conclusions might be drawn from the same data. Altogether the work is most welcome as a fund of material for more general treatment, and should encourage the study and publication of prehistoric finds in England.

\section{THE FORTHCOMING TOTAL SOLAR} ECLIPSE.

$\mathrm{B}^{\mathrm{Y}}$ the time that Nature appears next week, the total solar eclipse of August 30 will have become an event of the past, and we hope then to be in a position to announce that the careful preparations, which have occupied the minds of astronomers for so many months past, have been crowned with success.

Since the appearance of Dr. Lockyer's article concerning the eclipse, in our issue of February 23, several important modifications in the proposed arrangements have been made, but most of the eclipse observers are now at their stations erecting or adjusting their instruments for the final scene on Wednesday next. How much depends on the nicety of these adjustments can only be understood by those intimately concerned; but when it is recalled that since the general introduction of photographic methods into eclipse work the sun has only been eclipsed for about half an hour, that the duration of totality in the coming event exceeds $3 \frac{3}{4}$ minutes, and that no favourable opportunity. will occur again until I9I2, when totality will only last for about 60 seconds, some idea may be obtained of the anxiety of those observers who are fortunate enough to take an active part in next Wednesday's observations.

Subjoined to this article is a letter from Dr. W. J. S. Lockyer describing the preliminary operations of the eclipse expedition of the Solar Physics Observatory, under the personal direction of Sir Norman Lockyer, K.C.B. When all arrangements for this expedition were nearly completed, but before Sir Norman Lockyer left England, it was decided by the French Government, in quite a friendly spirit, that the presence of a foreign man-of-war in Philippeville harbour was not desirable at the present time; therefore arrangements were made with the Spanish authorities, who rendered such valuable help to the similar expedition in 1900 , for the party to go to Palma. Some of the work contemplated at Palma is described by Dr. Lockyer in his letter.

Some novel observations will be made by other observers. In a recent communication to the British Astronomical Association Mr. C. E. Stromeyer pointed out that geodesy might be assisted by an accurate determination of the path of totality. This path has been computed on the assumption that the earth has a certain form, and if the computed values are found to be incorrect, the errors in the assumption might be discovered. Another valuable suggestion was made in a letter from Dr. Johnstone Stoney which appeared in these columns on July $\mathrm{I}_{3}$, wherein the writer pointed out that the planet Mercury will be very near to a line joining the earth and the sun, and will therefore present a very thin crescent to the observer's view. No. I 869 , vOL. 72]
If Mercury has an atmosphere, the horns of the crescent should appear prolonged by atmospheric refraction, and a careful observer, suitably equipped, should be able to detect the prolongation, and possibly to observe the spectrum of the tips.

M. Touchet suggests that the moon might be observed, both before the first and after the fourth contacts, projected on the brighter portions of the lower corona, by an observer employing a suitable dark glass with a small telescope.

In a brochure recently received from Señor Horacio Bentabol, of Madrid, the author makes a number of suggestions to eclipse observers by which the existence of a lunar atmosphere might be detected. Among other matters he suggests that delicate thermometric observations made for some hours before and after the eclipse might exhibit a heat-absorption effect due to the interposition of the lunar atmosphere, between the sun and the observer, before the actual body of the moon was interposed. Solar radiation observations might also exhibit the same effect. Photometric observations of the illumination of the sky might show an analogous absorption of light, due to the lunar atmosphere. Exact determinations of the solar diameter would, if the moon possesses an atmosphere, probably show the results of the refraction due to that atmosphere. The apparent hourly movement of the sun should become modified, as the lunar atmosphere is interposed, for the same reason. Many other points whereby the existence of such an atmosphere might be tested are given by Señor Bentabol.

As recently mentioned in these columns, French astronomy will be well represented at the various stations, whilst American astronomers have journeyed to a number of widely separated stations. Three expeditions have been sent from the Lick Observatory to Labrador, Spain, and Egypt respectively. At each station a search is to be made for an intraMercurial planet, and large-scale coronagraphs of exactly similar construction are to be employed. Should any actual movements take place in the corona during the two and a half hours which elapse between totality at Labrador and at Assouan, the photographs obtained at these respective stations should show it.

The Canadian Government has dispatched an expedition to Labrador, and has officially invited Mr. and Mrs. E. W. Maunder to accompany the same. Mrs. Maunder will employ a coronagraph exactly similar to that which Prof. Turner is using in Egypt.

The details concerning the regions crossed by the eclipse track, and the times of totality, \&c., have already been given in many places, but the subjoined table griving the times and magnitude of the greatest phase in these islands may be of interest :-

\begin{tabular}{|c|c|c|c|c|c|}
\hline & $\begin{array}{l}\text { Eclipse begins } \\
\text { d. h. m. }\end{array}$ & $\begin{array}{l}\text { Greatest eclips } \\
\text { d. h. m. }\end{array}$ & & $\begin{array}{l}\text { Eclipse ends } \\
\text { d. h. m. }\end{array}$ & \\
\hline & 292349 & $\cdots \quad 30$ I 4 & $\cdots$ & 30215 & $\cdots$ \\
\hline E & $2923 \quad 44$ & $30 \circ 55$ & $\ldots$ & 3024 & $\ldots$ \\
\hline & $\begin{array}{lll}29 & 23 & 39\end{array}$ & $30 \circ 53$ & $\ldots$ & 302 & $\ldots$ \\
\hline
\end{tabular}

In the above table, which is taken from the Com panion to the Observatory, the times are Greenwich Mean Time, which is reckoned from the previous mean noon, and the magnitude is given with the sun's whole diameter as unity.

\section{The Solar Physics Observatory Eclipse Expedition.}

Palma, August I8.

We have now been at Palma a week to-day, and are all thoroughly settled down, not only at the very excellent hotel in which we are located, but at the eclipse camp, which lies about a mile towards the north-west. We are a large party. There are 
I50 volunteers from H.M.S. Venus, including the captain and all the officers, and we ourselves total six, namely, Sir Norman Lockyer, Mr. C. P. Butler and myself, and three volunteer observers, Lady Lockyer, Mr. Howard Payn, and Mr. Frank McClean.

We arrived here on the morning of August Io, having transhipped at Gibraltar to H.M.S. Venus about noon on August 8 . The arrangements for transferring the I ro packing cases from ship to ship were all that could be desired, an Admiralty lighter and tug being in readiness on our arrival. By five o'clock in the afternoon we were steaming away towards our destination, leaving behind us that great pile of rock, which eventually became a dim speck on the horizon.

Needless to say, the conversations in the captain's cabin, in the wardroom, and in many other parts of the ship were concentrated on eclipse matters, and this culminated in a lecture which I was requested to give to the whole available ship's company. The keenness displayed was universal, and the following day volunteers were called for to assist in the work for the eclipse, and, as I have previously mentioned, they now total $1_{5}$ o. The same evening Sir Norman Lockyer gave a lecture, which increased, if possible, the keenness previously displayed.

On our arrival at Palma, which, by the way, is situated in a beautiful bay with an excellent anchorage, the ship was boarded by numerous officials after the customary salutes had been exchanged between the ship and the fort. Amongst those who came on board was our friend Mr. Howard Payn, who had preceded us in order to fix on a suitable site for our camp, to arrange for local labour and material, and to smooth things generally for us. The very admirable way in which this difficult and delicate task was accomplished by him in conjunction with Mr. Roberts, the British Consul at Barcelona, could not be surpassed, and all the members of the expedition are unanimous in singing their praises. For the expedition to Spain in Igoo Mr. Payn rendered a similar service, and on that occasion the arrangements he made were all that could be desired.

On the afternoon of our arrival at Palma, Sir Norman Lockyer and Captain Eyres, in the company of the British Vice-Consul, Mr. Bosch, paid some official visits, and afterwards the site selected by $\mathrm{Mr}$. Payn was visited. This site is an ideal spot for a large eclipse camp, being sufficiently close to a landing stage for boats, walled in, and perfectly open for astronomical observations in all directions. The ground, which is private property, has been kindly lent by the owner for the purposes of the eclipse observations, and the members of the expedition are extremely grateful for the use of such an admirable camping locality.

Indeed, kindness itself has been displayed in every direction. All the authorities of the island have laid themselves out to supply anything that is required, and already these offers have been accepted in several ways.

On the early morning of August in work at the camp began in earnest. The tents, loaned to us by the War Office, were taken ashore and erected, and later in the day the packing cases were landed and carried by carts to the ground. Parties from the ship soon began to be acquainted with the contents of the cases they had so delicately handled, and by the evening the large wooden structure composing the dark room and the camera end of the prismatic reflector, and also the siderostats and coelostat huts, were nearly all erected and covered. While this work was in progress, meridian lines were being pegged out and the positions for the concrete pillars fixed.
The erection of the piers for the instruments commenced on the following day, and so soon as these were completed the instruments which were to be placed on them were put together and set up.

At the time of writing (August 18, ro p.m.) great progress has been made; most of the instruments are nearly erected, some are in approximate adjustment, while they are now all under canvas, the coverings having been set up in truly nautical style.

To gain some idea of the work undertaken, it may be mentioned that the larger instruments include a prismatic reflector of 76 feet focal length, a 6-inch three-prism prismatic camera, two coronagraphs (one I6 feet focal length) and an objective grating camera worked in connection with one cœlostat, a triple camera of 3-inch aperture and 12 feet focal length for photographing the eclipsed sun in colours, and a $3 \frac{1}{2}$-inch coronagraph worked equatorially. Already each instrument has a party from the ship to assist in working it efficiently, and these are daily in the camp to render aid when necessary.

- In addition to the above-mentioned assistants for the instruments, there are several other pieces of work which are being taken in hand. Thus the disc party has already erected discs of various sizes on imposing structures on the east side of the ground. Further, there are groups of observers for sketching the corona without discs, making star observations, recording the colours of the corona and landscape, observing the shadow-bands and sweep of the shadow, making meteorological observations, \&c.

These and other parties are daily being drilled to render them as efficient as possible, and there is every hope that eclipse day will find them skilled and accurate observers.

We are, however, rather doubtful as to the kind of weather that will be experienced here on the eventful day. So far, the chances have been in our favour, but partially clouded skies are more common than one would like to see. A sharp thunderstorm broke over the town on the early morning of August 17, and rain fell in torrents. Fortunately there was no wind, and no damage was done. Those acquainted with the local weather conditions cheer us up by forecasting fine weather, but clouds are far more frequent than one would wish them, and the prospects are not nearly so good as they were in India in 1898 or Spain in I9oo. In less than a fortnight's time our fate will be sealed.

In addition to our party, numerous other observers of different nationalities are taking or have taken up their stations in the neighbourhood of the town.

\section{William J. S. LOCKYER.}

\section{FIRST INTERNATIONAL CONGRESS OF} ANATOMISTS.

THE first meeting of the Congrès fédératif international d'Anatomie was held in Geneva, and commenced on the morning of Sunday, August 6, by the opening of an exhibition of specimens and appliances illustrating recent progress in anatomy. The congress closed on the evening of Thursday, August Io, when three hundred members and adherents of the congress were entertained by the city of Geneva to an official banquet. The congress represented a conjoint meeting of the five leading anatomical societies-the Anatomical Society of Great Britain and Ireland, Anatomische Gesellschaft, Association des Anatomistes, Association of American Anatomists, and the Unione Zooligica Italiana. Almost every country was represented. Switzerland itself contributed more than roo members, France 66, Germany and Austria 36, Great Britain

$$
\text { NO. I869, VOL. } 72 \text { ] }
$$

